\title{
Functional properties of dried tarragon affected by drying method
}

\author{
Koç, B.*; Çağlar, N.; Atar, G.
}

${ }^{a}$ Gaziantep University, Faculty of Fine Arts, Dep. of Gastronomy and Culinary Arts, Gaziantep, Turkey

*kocbanu@gmail.com

\begin{abstract}
Tarragon is a small shrubby perennial herb in the Asteraceae family. It is cultivated for the use of its aromatic leaves in seasoning, salads, sauces, vinegars, mustard and spices. In this study, tarragon was dried in two different drying equipment (infrared (ID) and microwave dryers (MD)) to compare the drying and final product properties (moisture content, water activity and colour change). Three different output power levels of 125, 250 and $500 \mathrm{~W}$ were used for $M D$, whereas the ID treatment involved three drying temperature levels that were 60,70 and $80^{\circ} \mathrm{C}$. A comparison of the drying kinetics, MD was more effective in shortening drying time when compared with ID.
\end{abstract}

Keywords: Tarragon, microwave drying, infrared drying, color change 


\section{Introduction}

Herbs and spices are used to season foods throughout the world. These are the aromatic substances that enhance savoury character as flavouring agents and as appetite stimulants. The use of spices has increased significantly over the past years, partly due to renewed interest in dishes that use a wide variety of spices. Tarragon (Artemisia dracunculus L.) is a medicinal and aromatic plant that extends all over Eurasia. Tarragon is an herbaceous plant of the Asteraceae family. It is a strong aromatic plant and is also considered as a medicinal plant [1]. Two varieties of tarragon can be distinguished [2; 3]: French Tarragon and Russian Tarragon. French Tarragon of the South European origin is mainly used as a culinary herb in oils, sauces, vinegars, mustard and spices [4; 5]. Tarragon can be consumed as fresh, dried and frozen product. Drying is the main step in the preparation of tarragon for marketing. Not enough data is available in the literature about drying and storage of tarragon.

Correct drying of aromatic plants is necessary for high quality and stable products. The final moisture content (MC) must reach $5-10 \%$. Colour is an important component of quality throughout agriculture and food industry, because colour is closely associated with factors such as freshness, ripeness, desirability and food safety. It is often the primary consideration of consumers when making purchasing decisions. A limited amount of information was found about the stability of dried tarragon and the colour change after drying. Some of tarragon's aspects are lost when it is dehydrated, though, and its colour deteriorates. There has been much research into microwave drying techniques, examining a broad spectrum of fruits and vegetables [6] and others, however, more data are still needed on the effect of microwave drying on the potential role of medicinal plants.

Mathematical modelling of drying processes and kinetics is a tool for process control and can be used to choose suitable method of drying a specific product. The developed models can be used to design new drying systems, determine optimum drying conditions and to accurately predict simultaneous heat and mass transfer phenomena during the drying process. Taking into account the above-mentioned considerations, this study was designed with the objectives to (1) determine the drying characteristics and quality degradation in terms of colour, moisture content and water activity of tarragon subjected to the two drying methods; and (2) examine and compare the applicability of eleven different thin-layer models to the simulation of moisture loss in tarragon during drying.

\section{Materials and Methods}

\subsection{Material}

Fresh tarragon leaves of uniform maturity were purchased from the local market at Gaziantep. They were handpicked and cleaned, washed in sufficient tap water twice to remove mud and 
other foreign matter and drained completely. The roots and mature stems were removed prior to washing.

\subsection{Drying}

Drying trials were carried out at three microwave generation power levels: 125, 275, and 625W by using a microwave dryer (Arçelik ARMD580, Turkey). The tarragon leaves (25 g) selected from uniform and healthy plants. Three drying trials were conducted at each power level. The values obtained from these trials were averaged and the drying parameters determined. The rotating glass plate was removed from the oven every $30 \mathrm{~s}$ during the drying period and moisture loss determined by weighing the plate using a digital balance (Mettler Toledo PM30, Germany) with 0.01 g precision.

A laboratory scale infrared dryer was used for infrared dehydration of the samples (OHAUS MB200, USA). Approximately $5 \mathrm{~g}$ of tarragon leaves were uniformly spread on a dish (12 $\mathrm{cm}$ diameter $3 \mathrm{~cm}$ height) The drying experiments were conducted at infrared temperatures levels of 60,70 and $80^{\circ} \mathrm{C}$. This drier is equipped with a temperature controller and an electronic balance with an accuracy of $\pm 1^{\circ} \mathrm{C}$ and $\pm 0.001 \mathrm{~g}$, respectively.

Three drying trials were conducted at each drying temperatures and power levels. Drying process continued until they reached equilibrium state, i.e. constant weight.

\subsection{Colour measurement}

The colour of fresh and dried leaves was determined by using colorimeter (Hunterlab Colorflex, USA). The results were expressed in accordance with the CIE Lab system. The total colour change $(\Delta \mathrm{E})$ of dried tarragon leaves with respect to fresh tarragon was calculated by Eq. (1).

$$
\Delta \mathrm{E}=\sqrt{\Delta L^{2}+\Delta a^{2}+\Delta b^{2}}
$$

\subsection{Moisture content}

Moisture content was determined by drying a sample in an air oven at $105^{\circ} \mathrm{C}$ until constant mass was obtained.

\subsection{Water activity}

Water activity was measured with a water activity measurement device (Rotronic, HP23AW-A, New York) with a 0.0001 sensitivity.

\subsection{Mathematical modelling of drying curves}

A few theoretical, semi-theoretical and empirical drying models have been reported in the literature. The most frequently used type of model for thin layer drying is the lumped 
parameter type, such as the Newton equation [9-11]. The moisture ratio during drying is determined using equation (2):

$$
M R=\frac{M_{t}-M_{e}}{M_{0}-M_{e}}
$$

where, $\mathrm{M}_{\mathrm{t}}$ is the moisture content of the product at any time, Me is the equilibrium moisture content, $\mathrm{M}_{0}$ is the initial moisture content all in $\mathrm{kg}$ water/kg dry matter.

In this analysis, it was assumed that the moisture gradient driving force during drying is a liquid concentration gradient; meanwhile the effect of heat transfer was neglected as a simplifying assumption. For all experimental conditions, the value of $\left(M_{t}-M_{e}\right) /\left(M_{0}-M_{e}\right)$, a dimensionless moisture content was obtained. Because samples were not exposed to uniform relative humidity and temperature continuously during drying, the moisture ratio was simplified as recommended by [7] expressed as follow:

$$
M R=\frac{M_{t}}{M_{0}}
$$

For mathematical modelling, the equations in Table 1 were tested to select the best model for describing the drying curve equation of the tarragon. The moisture ratio of the tarragon leaves during drying was calculated using equation (3). The goodness of fit of the tested mathematical models on the experimental data was evaluated using coefficient of determination $\left(\mathrm{R}^{2}\right)$, mean relative percentage deviation $(\mathrm{P})$ value and the percentage root mean squares error (RMSE) value with higher $\mathrm{R}^{2}$ values and lower RMSE and $\mathrm{P}$ values indicating a better fit [8] as follow:

$$
\begin{gathered}
\mathrm{P}=\frac{100}{N} \sum_{i=1}^{N} \frac{\mid \text { Mexp }-M \text { cal } \mid}{M \exp } \\
\text { RMSE }=\sqrt{100 \frac{\sum(\text { Mexp }-M c a l)^{2} / M \exp }{N}}
\end{gathered}
$$

where $\mathbf{M}_{\exp }$ and $\mathbf{M}_{\mathrm{cal}}$ are experimental and predicted moisture content values, respectively, and $\mathrm{N}$ is the number of experimental data. A model was considered acceptable if the $\mathrm{P}$ values and RMSE values were below $10 \%$ and $R^{2}$ values were higher than 0.90 .

\section{Result and Discussion}

Microwave drying trials were conducted at output power levels of 125, 275 and $625 \mathrm{~W}$ and the influence of each microwave power level on moisture ratio over drying time presented in Fig. 1a. The drying time decreased as microwave power level was increased. The times required for the moisture content of tarragon leaves to decrease from 7.897 to $0.097 \%$ (d.b) were 188, 60 and $40 \mathrm{~min}$ at microwave output power levels of 125, 275 and 625W, respectively. The effect of microwave power level of decreasing drying time was observed by $[23,24]$. The results indicate that mass transfer is more rapid at higher microwave power 
levels because more heat is generated within the sample, creating a larger vapor pressure differential between the interior and the surface of the product [25].

Table 1. Mathematically models used for modelling of drying curves

\begin{tabular}{|c|c|c|c|}
\hline Model Name & Model Equation & & Reference \\
\hline Lewis-Newton & $M R=\exp \left(-\mathrm{k}^{*} \mathrm{t}\right)$ & (4) & [9] \\
\hline Page & $M R=\exp \left(-\mathrm{k}^{*} \mathrm{t}^{\mathrm{n}}\right)$ & (5) & [10] \\
\hline Modified Page & $M R=\exp \left(-\left(\mathrm{k}^{*} \mathrm{t}\right)^{\mathrm{n}}\right)$ & (6) & [11] \\
\hline Henderson and Pabis & $M R=\mathrm{a} * \exp (-\mathrm{k} * \mathrm{t})$ & (7) & [12] \\
\hline Logarithmic & $M R=\mathrm{a} * \exp (-\mathrm{k} * \mathrm{t})+\mathrm{c}$ & (8) & [13] \\
\hline Two-Term & $M R=\mathrm{a} * \exp \left(-\mathrm{k}_{0} * \mathrm{t}\right)+\mathrm{b} * \exp \left(-\mathrm{k}_{1} * \mathrm{t}\right)$ & (9) & [14] \\
\hline $\begin{array}{l}\text { Two-Term } \\
\text { Exponential }\end{array}$ & $M R=\mathrm{a} * \exp \left(-\mathrm{k}^{*} \mathrm{t}\right)+(1-\mathrm{a}) * \exp \left(-\mathrm{k}^{*} \mathrm{a} * \mathrm{t}\right)$ & (10) & {$[15]$} \\
\hline Diffusion Approach & $M R=\mathrm{a} * \exp \left(-\mathrm{k}^{*} \mathrm{t}\right)+(1-\mathrm{a}) * \exp \left(-\mathrm{k}^{*} \mathrm{~b} * \mathrm{t}\right)$ & (11) & [16] \\
\hline $\begin{array}{l}\text { Modified Henderson } \\
\text { and Pabis }\end{array}$ & $M R=\mathrm{a} * \exp \left(-\mathrm{k}^{*} \mathrm{t}\right)+\mathrm{b} * \exp (-\mathrm{g} * \mathrm{t})+\mathrm{c} * \exp (-\mathrm{h} * \mathrm{t})$ & $(12)$ & [17] \\
\hline Verma & $M R=\mathrm{a} * \exp \left(-\mathrm{k}^{*} \mathrm{t}\right)+(1-\mathrm{a}) * \exp (-\mathrm{g} * \mathrm{t})$ & (13) & [18] \\
\hline Midilli and Küçük & $M R=\mathrm{a} * \exp \left(-\mathrm{k}^{*} \mathrm{t}^{\mathrm{n}}\right)+\mathrm{b} * \mathrm{t}$ & (14) & [19] \\
\hline
\end{tabular}

Infrared drying trials were conducted at radiation temperature levels of 60,70 and $80^{\circ} \mathrm{C}$. A graph of moisture ratio versus drying time during the infrared drying of tarragon leaves at different temperature levels is presented in Fig. 1b. From the data, moisture ratio decreased over drying time. Furthermore, infrared radiation temperature level influenced the change in moisture ratio of tarragon leaves. The results also showed that when infrared radiation temperature level increases, the time taken to dry tarragon leaves greatly decreased. Accordingly, the drying times required to reduce the moisture content of tarragon leaves to approximately $0.115 \%$ (w.b) were 126, 88 and 66 min when infrared temperature levels of 60,70 and $80^{\circ} \mathrm{C}$, respectively, were applied. A decrease in drying time with increased infrared temperature level has also been reported by other researcher [20].

From these findings it could be stated that drying time for tarragon leaves at $80^{\circ} \mathrm{C}$ was 2 times shorter than that of $60^{\circ} \mathrm{C}$. The experiments data showed that drying time for tarragon leaves at $625 \mathrm{~W}$ was 4 times shorter than that of $125 \mathrm{~W}$.

The eleven different MR models used to predict the moisture content as a function of drying time are presented in Table 1. The coefficient of determination $\left(\mathrm{R}^{2}\right)$, the RMSE and $\mathrm{P}$ value were used to assess how well the models characterized the drying curves. The statistical analysis of the models for a given set of drying conditions are shown in Table 2. An analysis of variance indicated that the microwave power and infrared temperature levels significantly affected the drying parameters. Higher microwave power and infrared temperature levels are associated with significant decrease in drying time and moisture ratio which was much more noticeable in microwave than infrared drying. This has been demonstrated in the studies of Azzouz et al. [21]. On the other hand, among the eleven models, the Midilli and Küçük, 
model provided the best fit to the microwave and infrared radiation drying data as indicated by a higher $\mathrm{R}^{2}$ and lower RMSE and $\mathrm{P}$ value than those of the other models.

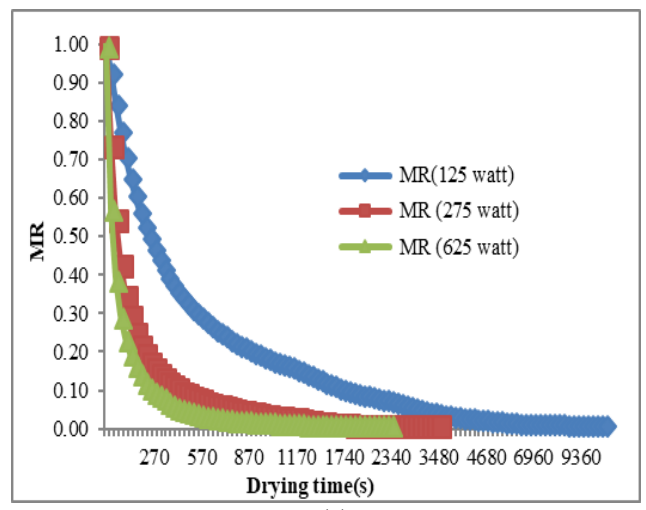

(a)

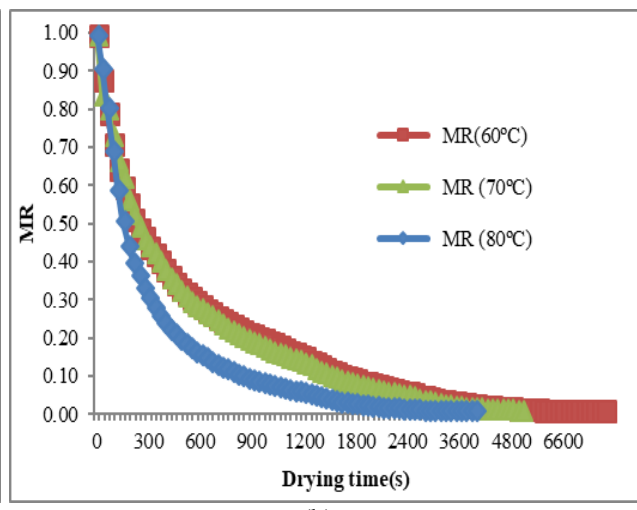

(b)

Fig. 1 Variations of moisture ratio as a function of time for different a) infrared drying temperatures, b) microwave drying power

Table 2. Statistical analysis of drying models at various infrared temperatures and microwave powers

\begin{tabular}{|c|c|c|c|c|c|c|c|c|c|c|c|c|}
\hline & \multicolumn{12}{|c|}{ Equation No } \\
\hline & & 4 & 5 & 6 & 7 & 8 & 9 & 10 & 11 & 12 & 13 & 14 \\
\hline \multirow{3}{*}{$60^{\circ} \mathrm{C}$} & $\mathrm{R}^{2}$ & 0.92 & 1.00 & 1.00 & 0.96 & 0.98 & 1.00 & 0.96 & 1.00 & 1.00 & 1.00 & 1.00 \\
\hline & \%RMSE & 1.32 & 0.14 & 0.14 & 0.79 & 0.38 & 0.23 & 0.88 & 0.24 & 0.23 & 0.24 & 0.02 \\
\hline & $\mathrm{P}$ & 60.2 & 15.5 & 15.5 & 49.7 & 40.6 & 18.0 & 52.1 & 18.9 & 18.0 & 18.9 & 0.82 \\
\hline \multirow{3}{*}{$70^{\circ} \mathrm{C}$} & $\mathrm{R}^{2}$ & 0.93 & 1.00 & 1.00 & 0.97 & 0.98 & 1.00 & 0.97 & 1.00 & 1.00 & 1.00 & 1.00 \\
\hline & \%RMSE & 1.17 & 0.06 & 0.06 & 0.67 & 0.46 & 0.06 & 0.69 & 0.09 & 0.06 & 0.09 & 0.02 \\
\hline & $\mathrm{P}$ & 52.2 & 13.1 & 13.1 & 40.5 & 33.1 & 11.4 & 41.0 & 12.3 & 11.4 & 12.3 & 2.15 \\
\hline \multirow{3}{*}{$80^{\circ} \mathrm{C}$} & $\mathrm{R}^{2}$ & 0.97 & 0.99 & 0.99 & 0.97 & 0.99 & 1.00 & 0.99 & 1.00 & 1.00 & 1.00 & 0.99 \\
\hline & \%RMSE & 1.03 & 0.33 & 0.33 & 0.86 & 0.39 & 0.11 & 0.63 & 0.10 & 0.11 & 0.10 & 0.08 \\
\hline & $\mathrm{P}$ & 54.7 & 26.6 & 26.6 & 50.3 & 37.2 & 9.57 & 43.5 & 7.80 & 9.57 & 7.80 & 13.8 \\
\hline 125 & $\mathrm{R}^{2}$ & 0.94 & 0.99 & 0.99 & 0.96 & 0.98 & 1.00 & 0.97 & 1.00 & 1.00 & 1.00 & 1.00 \\
\hline \multirow{2}{*}{ Watt } & \%RMSE & 1.33 & 0.34 & 0.34 & 1.00 & 0.46 & 0.17 & 0.90 & 0.17 & 0.17 & 0.17 & 0.08 \\
\hline & $\mathrm{P}$ & 56.4 & 26.5 & 26.5 & 50.4 & 47.3 & 13.6 & 48.8 & 13.9 & 13.6 & 13.9 & 14.5 \\
\hline \multirow{3}{*}{$\begin{array}{r}275 \\
\text { Watt }\end{array}$} & $\mathrm{R}^{2}$ & 0.94 & 0.99 & 0.99 & 0.95 & 0.98 & 1.00 & 0.96 & 1.00 & 1.00 & 1.00 & 0.99 \\
\hline & \%RMSE & 1.31 & 0.27 & 0.27 & 1.11 & 0.72 & 0.13 & 0.95 & 0.13 & 0.13 & 0.13 & 0.19 \\
\hline & $\mathrm{P}$ & 78.0 & 40.6 & 40.6 & 73.6 & 73.9 & 29.9 & 71.4 & 29.9 & 29.9 & 29.9 & 19.6 \\
\hline & $\mathrm{R}^{2}$ & 0.93 & 1.00 & 1.00 & 0.94 & 0.97 & 1.00 & 0.96 & 1.00 & 1.00 & 1.00 & 1.00 \\
\hline \multirow{2}{*}{ Watt } & oRMSE & 1.21 & 0.21 & 0.21 & 1.07 & 0.89 & 0.22 & 0.95 & 0.22 & 0.22 & 0.22 & 0.10 \\
\hline & P & 85.2 & 45.5 & 45.5 & 83.3 & 80.6 & 43.4 & 80.6 & 43.4 & 43.4 & 43.4 & 3.93 \\
\hline
\end{tabular}

Water activity of the dried tarragon leaves at different infrared temperatures and microwave power are given in Table 3. Water activity decreased as temperature increased in the infrared dryers. In addition, water activity decreased as microwave power increased in the microwave dryers.

The impact of various drying techniques upon the colour parameters of the dried tarragon leaves was exhibited in Table 3 . The $L$ value of all the dried tarragon declined considerably 
when compared with the fresh tarragon. Additionally, temperature and/or microwave power rise significantly prompted the decline of $L$ values and surge of a values which may be by reason of non-enzymatic browning reaction. Among the used microwave drying, the highest $a$ value was obtained by the microwave drying at $125 \mathrm{~W}$, while the lowest $a$ value loss was obtained by the microwave drying at $625 \mathrm{~W} . \Delta \mathrm{E}$ is a function of a, b and $\mathrm{L}$ values, and it was reliant on drying techniques. Microwave drying technique at $275 \mathrm{~W}$ resulted in the highest $\Delta \mathrm{E}$ while lowest $\Delta \mathrm{E}$ value was attained from the infrared drying technique at $80^{\circ} \mathrm{C}$.

Table 3-Comparison between infrared temperatures and microwave power for colour parameters and $a_{w}$ values

\begin{tabular}{|c|c|c|c|c|c|}
\hline & $\mathbf{a w}_{\mathbf{w}}$ & $\mathbf{L}$ & $\mathbf{a}$ & b & $\Delta \mathbf{E}$ \\
\hline Fresh & - & $35.15^{\mathrm{a}} \pm 2.18$ & $-8.02^{\mathrm{b}} \pm 0.20$ & $12.17^{\mathrm{ab}} \pm 0.19$ & - \\
\hline $60^{\circ} \mathrm{C}$ & $0.565 \pm 0.004$ & $31.07^{b} \pm 0.18$ & $-5.96^{e} \pm 0.04$ & $11.77^{\mathrm{b}} \pm 0.19$ & 4,68 \\
\hline $7^{\circ} \mathrm{C}$ & $0.336 \pm 0.003$ & $31.91^{\mathrm{ab}} \pm 1.02$ & $-5.56^{e} \pm 0.05$ & $12.10^{\mathrm{ab}} \pm 0.08$ & 4.07 \\
\hline $80^{\circ} \mathrm{C}$ & $0.332 \pm 0.013$ & $32.68^{\mathrm{c}} \pm 1.02$ & $-6.11^{\mathrm{d}} \pm 0.57$ & $12.57^{\mathrm{a}} \pm 0.63$ & 3.15 \\
\hline 125 Watt & $0.364 \pm 0.001$ & $31.02^{b} \pm 0.10$ & $-4.87^{a} \pm 0.13$ & $11.84^{\mathrm{b}} \pm 0.11$ & 5.20 \\
\hline 275 Watt & $0.154 \pm 0.002$ & $30.58^{\mathrm{b}} \pm 0.64$ & $-5.46^{e} \pm 0.43$ & $12.17^{\mathrm{ab}} \pm 0.56$ & 5.23 \\
\hline 625 Watt & $0.095 \pm 0.002$ & $31.48^{\mathrm{ab}} \pm 1.07$ & $-6.57^{c} \pm 0.23$ & $12.56^{\mathrm{a}} \pm 0.19$ & 3.96 \\
\hline
\end{tabular}

\section{Conclusions}

This study characterized the influence of drying conditions on the drying behaviour of tarragon leaves using infrared radiation and microwave drying. It was found that the drying rate increases substantially with the microwave power level or infrared temperature level used. The Midilli model was found to be more suitable for predicting the drying behaviour of tarragon leaves, with the values for $\mathrm{R}^{2}$ above 0.99 and with the lowest values of RMSE and $\mathrm{P}$ values for both drying methods. A comparison of microwave and infrared drying times indicate that irrespective of the power or radiation temperature applied, microwaving is an effective method of shortening the time required for drying to the desired moisture content without charring the samples. Moreover, microwave drying had less influence on the colour and rehydration ratio of the finished product than infrared drying.

\section{References}

[1] Simon, J.E.; Chadwick, A.F.; Craker, L.E..Herbs: an indexed bibliography, 1971 - 1980: the scientific literature on selected herbs and aromatic and medicinal plants of the temperate zone. Amsterdam, Elsevier; 1984.

[2] Vienne, M.; Braemer, R.; Paris, M.; Couderc H. Chemotaxonomic study of two cultivars of Artemisia dracunculus L.: ("French" and "Russian" Tarragon). Biochemical Systematics and Ecology 1989,17(5):373-374

[3] Yaichibe, T.; Masanori, K.; Kenichi, A. Morphological characters and essential oil in Artemisia dracunculus (French Tarragon) and Artemisia dracuncloides (Russian Tarragon). Tokyo Nogyo Daigaku Nogaku Shuho 1997, 41(4):229-238. 
[4] Deans, S.G.; Simpson, E.J.M. Artemisia dracunculus- Industrial profiles. Medicinal and Aromatic Plants 2002, (18):91-97.

[5] Ribnicky, D.M.; Poulev, A.; O'Neal, J.; Wnorowski, G.; Malek, D.E.; Jager, R.; et al. Toxicological evaluation of the ethanolic extract of Artemisia dracunculus L. for use as a dietary supplement and in functional foods. Food and Chemical Toxicology 2004, 42(4):585-598.

[6] Bouraout, M., Richard, P. and Durance, T. Microwave and convective drying of potato slices. Journal of Food Process Engineering 1994, 17, 353-363.

[7] Akgun, N.A.; Doymaz, I. Modelling of olive cake thin-layer drying process. Journal of Food Engineering 2005, 68: 455-461.

[8] Goyal, R.K.; Kingsly, A.R.P.; Manikantan, M.R.; Ilyas S.M. Mathematical modelling of thin layer drying kinetics of plum in a tunnel dryer. Journal of Food Engineering 2007, 79(1): 176-180.

[9] Ayensu, A. Dehydration of food crops using a solar dryer with convective heat flow. Solar Energy 1997, 59: 121-126.

[10] Page, G.E. Factors Influencing the Maximum Rates of Air Drying Shelled Corn in Thin Layers M.S. Thesis 1949, Department of Mechanical Engineering, Purdue University, Purdue, USA.

[11] Wang, C.Y.; Singh, R.P. A single layer drying equation for rough rice. ASAE Paper 1978, 78-3001, ASAE, St. Joseph, MI.

[12] Henderson, S.M.; Pabis, S.Grain drying theory. II. Temperature effects on drying coefficients. J. Agr. Eng. Res. 1961, 6:169-174.

[13] Toğrul, I.T.; Pehlivan, D. Mathematical modelling of solar drying of apricots in thin layers. J. Food Eng. 2002, 55:209-216.

[14] Henderson, S.M. Progress in developing the thin layer drying equation. Trans. ASAC 1974, 17:1167-1172.

[15] Sharaf-Eldeen, Y.I.; Blaisdell, J.L.; Hamdy, M.Y. A model for ear corn drying. Trans. ASAE 1980, 23(5): 1261-1265.

[16] Kassem, A.S. Comparative studies on thin layer drying models for wheat. In: Proceedings of the 13th International Congress on Agricultural Engineering 1996., vol. 6, 2-6 February, Morocco.

[17] Karathanos, V.T. Determination of water content of dried fruits by drying kinetics. J. Food Eng. 1999, 39: 337-344.

[18] Verma, L.R.; Bucklin, R.A.; Endan, J.B.; Wratten, F.T. Drying effects of drying air parameters on rice drying models. Trans. ASAE 1995, 85: 296-301.

[19] Akpinar, E.; Midilli, A. Bicer, Y. Single layer drying behaviour of potato slices in a convective cyclone dryer and mathematical modeling. Energy Convers Manage 2003, 44:1689-1705

[20] Sorour, H.; El-Mesery, H. Effect of microwave and infrared radiation on drying of onion slices. International Journal of Research in Applied 2014, 2(5):2347-4580.

[21] Azzouz, S.; Guizani, A.; Jomaa, W.; Belghith, A. Moisture diffusivity and drying kinetic equation of convective drying of grape. J. Food Eng 2002, 55: 323-330. 